\title{
INTERACTIVE MEANING POTENTIALS IN WEIGHT-LOSS WEB-ADVERTISING: THE FEMALE BODY IN CRISIS
}

\author{
Emily Lau Kui Ling \\ Department of English \\ Faculty of Languages and Linguistics \\ University of Malaya \\ elkl@um.edu.my
}

\begin{abstract}
The common saying, "a picture is worth a thousand words" is no longer questioned in the twenty-first century where information is extensively rendered in visual terms. The rise of digital capture devices and online social media presumes that visual culture is heading towards greater influence in every aspect of life. This paper explores the ways visual representations attract the viewer's attention, and based on Jewitt and Oyama's analytical framework of visual social semiotics seeks to understand the meaning-making potentials of weight-loss advertising. Three key factors: distance, contact, and point of view are shown to be crucial in creating complex and subtle relations between the represented and the viewer. I examine several images from a weight-loss website advertisement (www.acaiburnmax.com) to demonstrate how the semiotic resources of meaning making are comprehended, and more importantly, to expose the flawed gender message that only a slim, shapely, beautiful woman is attractive and succeeds in a heterosexual relationship.
\end{abstract}

\section{Keywords}

advertisements, semiotics resources, slimming, visual culture, website

\section{About the Author}

Emily Lau Kui Ling's research interests revolve around interdisciplinary studies with special attention to advertising and gender, and particularly, research on body image. 


\section{INTRODUCTION TO WEB-ADVERTISING}

The advertising landscape has undergone a dramatic change especially with the proliferation of digital capture devices and the tremendous growth of online social media. The innovation in online advertising continues to forge ahead, and is spurred by the rapid development of digital devices and fast-growing online social communities. Driven by profitable business opportunities, online advertisers are tapping into rich multimedia resources by investing in the technological boom of animation and interactive personalized responses or game-like sites.

Images are the most pervasive media formats on the internet and garner incredible attention for investment, particularly by the ad-networks. This is not surprising as image, in comparison with text, has several unique advantages. They are attractive, attention-grabbing, salient, and easily comprehensible. Bovee and Arens inform us that "most readers of advertisements (1) look at the illustration, (2) read the headline, and (3) read the body copy, in that order" (47). In light of the popularity of image-driven advertising, where the central force lies in visual approaches, web-advertising is indeed a very rich "text" to be studied.

Common to all ads are the visual and verbal elements; however, in web-ads, there are often additional functional objects on a web-page which are interactive elements. These interactive elements have two characteristics that serve to engage the viewer. They are either "heteroglossic items" (self-activating items or interactive items) or "monoglossic items" (unresponsive, static or inactive items) (Tan 97). In the case of Acaiburnmax.com web-ad, most of the visual and verbal elements are monoglossic items, except for two items on the top right of the web-page where there is an invitation to interact with the viewer. It says, "I'm online. Start chat." At the bottom of the page, there is a line that says, "Click here to see if you qualify for the AcaiBurn trial." Throughout the entire web-page, these two are the only two heteroglossic items that respond to mouse clicks in order to establish contact with the viewer. The potential of web-advertising is immense as it reaches out to the mass demographics of the internet generation in current, fluid, engaging and subtle ways (Tao, Hua, and Li). For this reason, the Acai Berry ad, nestled within the context of contemporary craze over slim and slender body, latches on the huge potential of web-advertising to communicate the message that its product is the "hottest new diet" and promotes what Acaiburnmax.com is calling a "breakthrough new formula that combines the scientific research of the West with the amazing antioxidant power of Acai berry."

In the past 50 years, investigations into the genre of advertising have been numerous, coming from journals that are business-oriented, from the humanities 
and social sciences, and even those that focus on medical issues. In the early 1960s, feminists began to question the roles women play in advertising. Betty Friedan, in her book The Feminine Mystique, pioneered this inquiry (Duffy). Following Friedan's insights, an interest in the portrayal of women within advertising blossomed (Budgeon). Two early works that look at advertising images are Judith Williamson's Decoding Advertisements and Erving Goffman's Gender Advertisements. Williamson illustrates the ideological process in advertising by which goods are given meaning. Goffman, on the other hand, demonstrates how commercial advertising mirrors and moulds concepts of masculine and feminine behavior. Both Williamson's and Goffman's investigations of print advertisements were groundbreaking works that pointed to the ideological nature of advertisements. Following these prominent works, academic investigation about the complex relationship of gender and advertising flourished.

In the same vein, this paper extends this investigation with the web-advertising genre and further develops on issues pertaining to the female body in crisis. Body advertising discourses promote a thin female body as a commodity that is easily acquired and vital to one's well-being and social worth. Moreover, changes in the images portrayed in mainstream media create confusion about what ideal female bodies should look like. One ideal focuses on a strong and healthy image, the image promoted in health and sports magazines; another is the image of voluptuous sex sirens, made mainstream through the popular media; while in the fashion world, the image of skinny models continues to thrive (Cohen). With these variations, it is hardly surprising that women feel ill at ease with their bodies, and are in a constant state of dissatisfaction (Orbach). At present, contemporary culture extends these conflicting voices through the discourse of health (Lau). Lau highlights that contemporary slimming ads legitimate the pursuit of slimming in the name of health (264-68). On the surface level, the discourse of healthy body promotes physiological health and well-being as the attributes of the ideal body. In so doing, the discourse of the healthy body appears to position aesthetic and relational concerns, such as the pursuits of beauty and heterosexual attractiveness, as being secondary to the primary goal of being healthy. The discourse of the healthy body has been allied to the discourses of beauty and heterosexuality to legitimize the pursuit of slimming as driven by a concern for health. The blurring of the orders of discourse endorses the complementary relationship between health, beauty, and female sexual attractiveness. In a careful examination of this concern, it is discovered that the discourse of the healthy body is not distinct from other discourses which promote the ideology of female sexual attractiveness; in fact, it is found to be covertly promoting this ideology. 
The grave concern in relation to the female body in crisis is the examination of how images of beautiful, excessively thin women foster feelings of dissatisfaction with one's body and overall looks (Moody-Hall; Stice and Shaw). One of the main sources which portray these ideals is slimming advertising. This is a specialized type of advertisement that offers either products or services to lose weight and promotes conformity to the stereotypical ideal figure. The slimming advertisements promote slimness as the ideal female beauty, possibly leading to an unhealthy body image among consumers. The prevalence of thin models portrayed in the slimming advertisements leads many women to feel dissatisfied and compels them to be engaged in weight-change behaviors. The pressure for women to achieve the ideal body shape may arise from comparisons of their own figure with the ideal figure as portrayed in the slimming advertisements. The slimming advertisements' depiction of slender models and their association with attractiveness, social acceptance, happiness, and success further reinforces women's insecurity and overestimation of their own body sizes. These ideologies are so rampant and so often repeated that they appear to be internalized by the uninformed minds as common sense and natural. When such a situation occurs, a condition called body dysmorphic disorder (BDD) begins to warp the minds of those affected. BDD, according to Veale, is defined as involving "a preoccupation with an imagined defect in one's appearance, a slight physical anomaly, or the person's concern is markedly excessive" (113). BDD affects both men and women; in women, it reinforces the desire to be thin since thinness is what the contemporary society regards as "beautiful". Consequently, women tend to overestimate their body sizes and may wish to reject their own bodies. Many researches pinpoint this as the main reason behind women's body dissatisfaction, and has contributed significantly to eating disorders, low selfesteem, and even depression (Caqueo-Urízar et al.; Leuvorasirikul; Orbach; O'pry; Moody-Hall; Myer and Biocca). It is reported that among various influences that predict the presence of eating disorder symptoms, slimming advertising in the mass media appears as the "strongest predictor" (Caqueo-Urízar et al. 78).

However, research into web-advertising images, in particular, is scarce. Therefore, a close examination of how web-advertising images work is much needed. This paper aims to do a close visual analysis of web-advertising in order to show how the discourse in web-advertising also contributes to the female body crisis: the relentless pursuit of slim ideals and the constant attempt to lose weight amongst women. This requires semiotic analysis to describe and explain uses of Internet media to advertise. As such, it is crucial to have a schema that is able to reveal the discourses of images. This will help in revealing messages (in the case of this study, gender messages) that are not initially apparent in the web-ad. The following section will delineate the aims and the approach used in this paper. 


\section{ANTI-FAT MESSAGES TO WOMEN IN WEB-ADVERTISEMENTS}

Within the context of anti-fat consumer culture, the female body is a commodity whose social currency is increasingly jeopardized by its failure to conform to an ideal of beauty: young, thin, toned, flawless, and healthy. The Internet, with its instantaneous and viral nature, contributes to maintaining, disseminating, and perpetuating the ubiquitous ideology of equating thinness with beauty and defining femininity in terms of an ideal female form. Bordo cautions us that weight preoccupation is "one of the most powerful normalising mechanisms of our century, insuring the production of self-monitoring and self-disciplining 'docile bodies"' (186). By examining the images of the female body in web-advertisements, we are able to see how the female body is in crisis with the centrality of visual culture in our contemporary society.

I use Jewitt and Oyama's analytical framework of visual social semiotics (henceforth, VSS) to systematically examine images of female bodies in a weightloss website advertisement on Acaiburnmax.com, and understand how they are exploited to convey gender messages of ideal female beauty. ${ }^{1}$ The VSS approach is chosen based on three key strengths: first, a social semiotic approach towards visual analysis provides a fine-grained and explicit method for analyzing the meanings established by the syntactic relations between people, places and things portrayed in images, second, this method is clear, systematic and replicable, and third, social semiotics takes into account the issues of power and the ideological function of images. This method facilitates the examination of how "images do not reflect 'reality' but construct it" (Jewitt 267).

By using VSS as an analytical framework in exploring the meaning potentials in web-advertising, this paper attempts to bridge several gaps in the existing literature: first, the paucity of research in analyzing visuals of web-advertisements. Second, the findings drawn from the VSS analysis are situated within a specific social context where gender issues are privileged. VSS is concerned with the study of images in their social contexts and hinge on the dialectical relationship between visual discourse analysis and semiotic practices where both influence the other. Semiotic analysis looks at images "not as evidence of the who, where, and what of reality, but as evidence of how their maker or makers have (re)constructed reality as evidence of bias, ideologically coloured interpretation, and so on" (van Leeuwen and Jewitt 5). Both points aptly address the gaps in the existing literature in the research on gender and visual culture.

Specifically, in this study, I explore the interactive dimension of meaning making potentials of visuals from weight-loss advertising, which need to be activated by both the producer and viewers of images. ${ }^{2}$ In this interactive dimension, three 
key factors: distance, contact, and point of view, are crucial in creating complex and subtle relations between the represented and the viewer. Figure 1 is a replication of Jewitt and Oyama's interactive dimension in social semiotic analysis of visual communication. ${ }^{3}$ I overlay a sociological interpretation (e.g. Goffman and Williamson) onto Jewitt and Oyama's descriptive framework; particularly investigating how women are constructed in weight-loss web-advertisements.

\section{Visual Analysis}

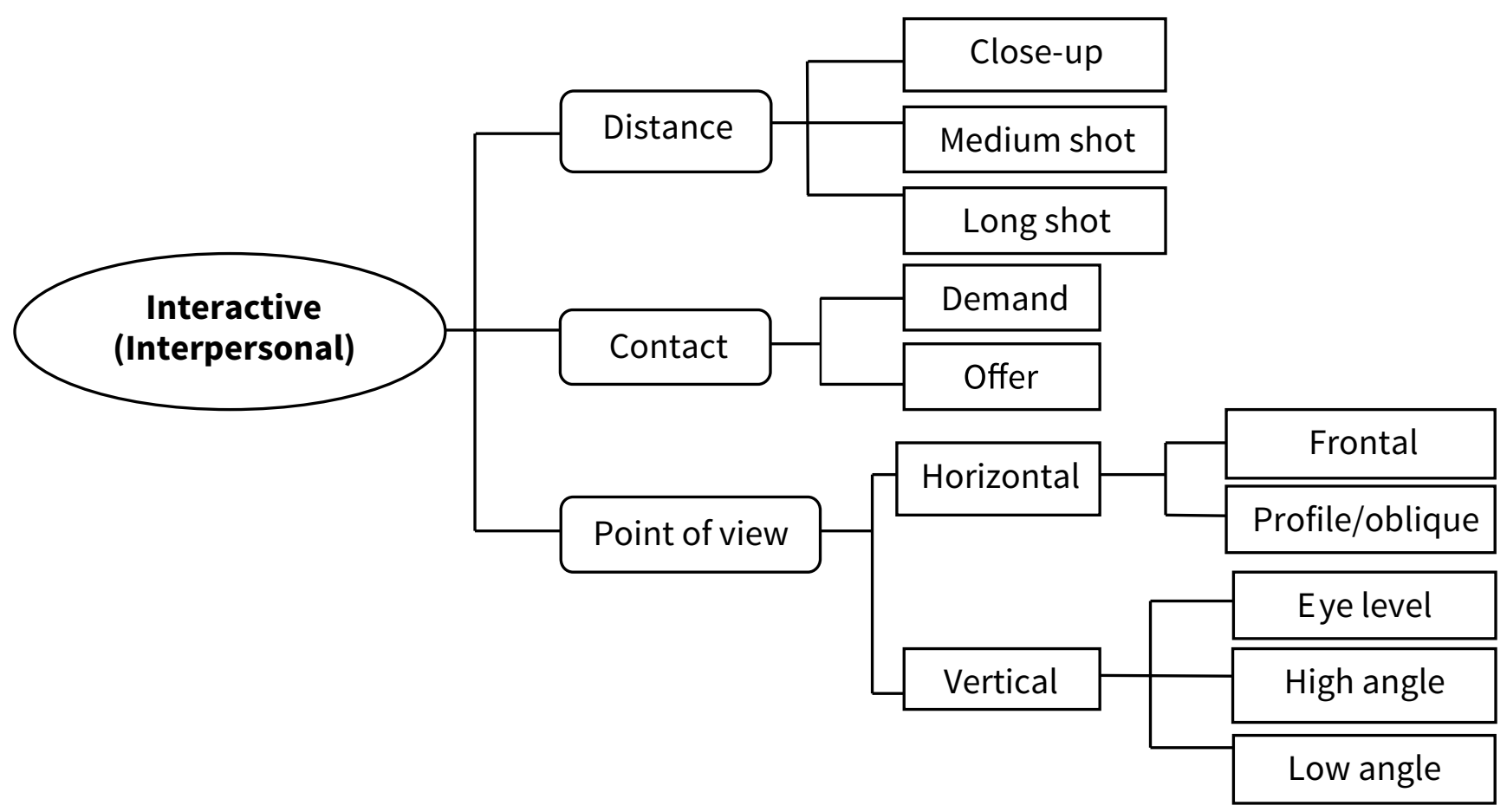

Fig. 1. "Interactive Dimension." Chart. Visual Meaning: A Social Semiotic Approach. Jewitt and Oyama. London: Sage Publications. 2001. 134-156. Print.

Interactive meaning refers to the relationship between the represented participant (the people, the places and things depicted in images) and the viewers. ${ }^{4}$ It is about how the image engages the viewers through three interactional structures: contact, distance, and point of view. Together they can create complex and subtle relations between the represented and the viewers. Each one of the three interactional structures is explained below, accompanied by an illustration.

I closely examine four images of women in the Acaiburnmax.com web-ad in order to disclose how images are used to capture the attention of the viewers, and for the purpose of promoting the product or service for weight loss and financial 
gain. More importantly, in demonstrating how the semiotic resources of meaning making are comprehended, it can also expose the gender message that only a slim, shapely beautiful woman is attractive and succeeds in a heterosexual relationship. This gender message is flawed for the following reasons: first, it implies that overweight or obese women are not physically attractive; second, it encourages women to evaluate their bodies and heterosexual desirability by adopting the male gaze, with the assumption that all men desire the same type of woman; and third, that all women want to appear desirable to men (Mulvey). ${ }^{5}$ Such discrimination and adoption of the male gaze function as a form of social control, which pressures women to adhere to a homogenizing and elusive ideal of femininity (Bordo; Bartky). Pienaar highlights that the discourse of female sexual attractiveness in this way legitimizes the "ethic of compulsory heterosexuality which positions women as erotic objects of the male gaze" (157). The VSS approach is one of the tools that can be employed to expose this flawed gender message in images.

\section{INTERACTIVE MEANING POTENTIALS IN WEIGHT-LOSS WEB-ADVERTISING}

Jewitt and Oyama tell us that, "[i]mages can create particular relations between viewers and the world inside the picture frame. In this way they interact with viewers and suggest the attitude viewers should take towards what is being represented" (145). Viewers are not passive. They interact with the images presented to them. This is how the interactive meaning potentials between the represented participant (the person or subject in the image) and the viewers can be established. From the three interactional structures: contact, distance and point of view,we see how the image engages the viewers. Through this, the web-advertiser convinces the viewers to adopt certain points of view and convinces them of how Acaiburn weight-loss products reduce weight effectively.

\section{Contact}

Jewitt and Oyama explain that when the people in the picture frame look directly at the viewer, they attempt to "make contact" with the viewers (145). This, in turn, establishes an "imaginary relation" between these two parties. According to Jewitt and Oyama, "the people in the picture symbolically demand something from the viewer. Facial expression and gestures then fill in what exactly they 'demand' in this way: they can demand deference, by unblinkingly looking down on the viewers, or pity, by pleadingly looking up at them; they can address viewers with an ingratiating smile or unsettle them with a penetrating stare." (145-146) 


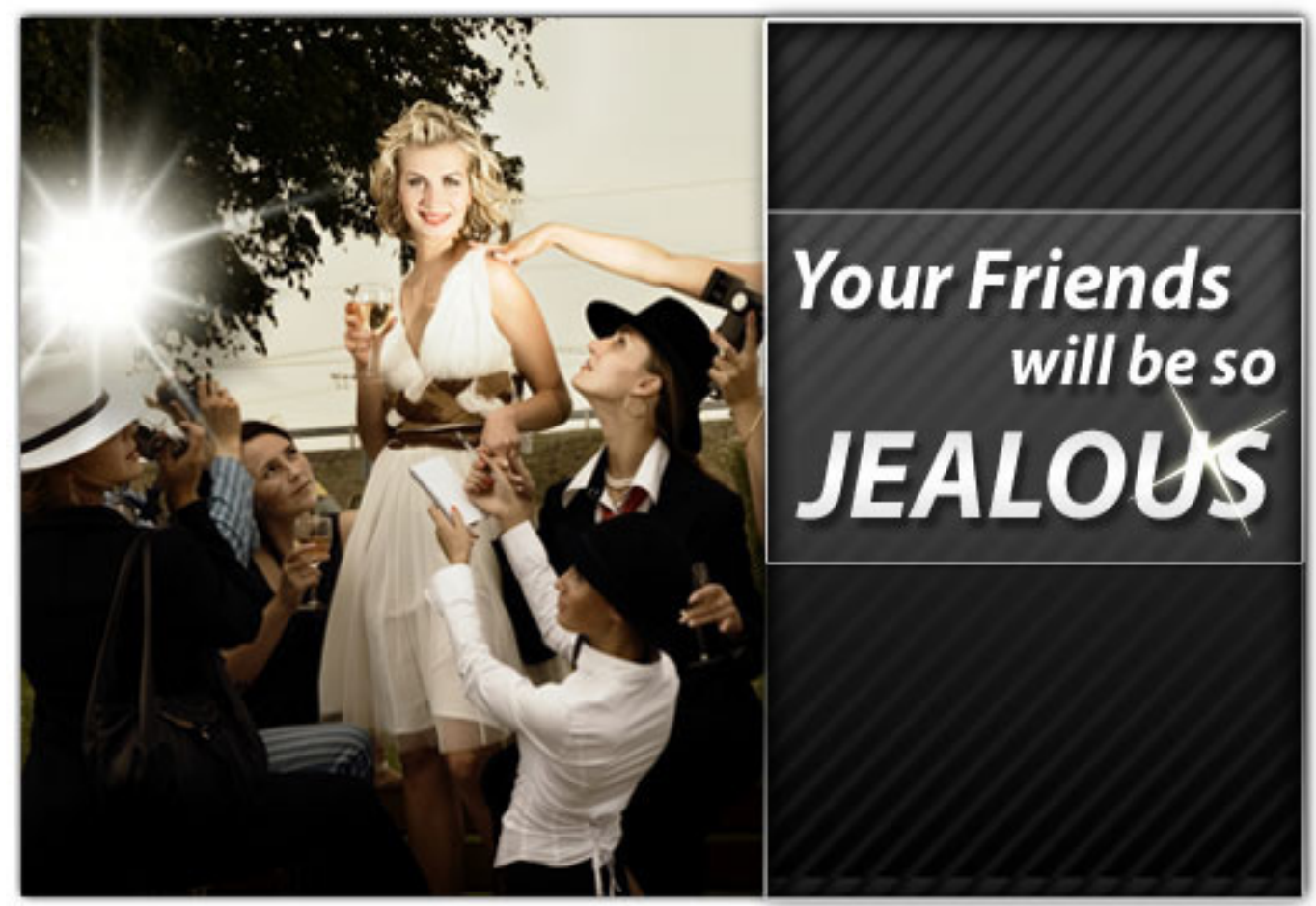

Fig. 2. Your friends will be so jealous, Acaiburnmax.com, n.d. Web, 27 August 2009.

Consider Figure 2. The woman in the white dress is looking directly at the viewers. She makes contact with them and establishes a connection. Her direct gaze, glowing facial expression, confident smile, and gestures fill in what she demands from viewers: their identification with her if they purchase and use the product. She exudes the confidence of a celebrity being idol-worshipped for possibly her good looks or achievement. Apparently, it is her breath-taking beauty which prompts the scene around her: we see people registering their admiration and adulation by the cameras flashing, audio-taping, pleading for an autograph, holding her hand, touching her shoulder and even offering her a drink. All of the people in this image are interacting with the woman, strengthening the message of celebrity worship.

Without this kind of "imaginary contact" we look quite differently at the people inside the picture frame. We "observe" them in a detached way and impersonally as though they are specimens in a display case. Kress and van Leeuwen call such pictures "offers" (124). In this light, the woman's gestures - smiling confidently, standing amidst the adoring crowd in her glamorous appeal - has both something to demand and to offer to the viewers. The information offered is that she is in high demand simply for her good looks; the viewers therefore, are drawn in to share her successful slim appeal. Through this kind of exchange of information between the 
represented and the viewers, the advertiser's message is conveyed: the Acaiburn products work $!^{6}$ The interactive meaning potentials are enacted: the woman in white makes eye contact with the viewers and establishes an imaginary relationship with them. She invites them into her glamorous world and the viewers are drawn in. Her svelte figure is the proof of the effectiveness of the Acaiburn products and she invites the viewers to be like her. The written text, "Your friends will be so jealous" reinforces the woman in white's popularity. It acts on the congenial peer relation of "friends" to further enhance the message. Again, this strikes a chord between the represented and the viewer. The viewer would certainly want to be like the woman in white as it will lead "friends" to have the same measure of admiration and adoration for her full and satisfying life. The contact, hence, is established by means of visual and written messages.

By visually reducing the representations of a woman's body to one prevailing image (the slim and trim ideals), weight-loss advertising asserts control over what women should look like. If they do not conform to the slim ideal, the female body is constructed as being in crisis or in constant need of weight-loss and shaping-up. Again, the female body as projected through the image bombards women with the message that who they are is synonymous with their appearances.

\section{Distance}

Another way of discerning the interactive meaning potentials can be seen in the "distance" of people, places or things as they appear to viewers. Distance can either narrow or expand the gap between the viewers and what is represented in the images. As in our day-to-day interactions, the norms of social relations decide the distance we keep from one another. This, according to Jewitt and Oyama, "translates into the 'size of frame' of shots." They further explain:

[t]o see people close up is to see them in the way we would normally only see people with whom we are more or less intimately acquainted. Every detail of their face and their expression is visible. We are so close to them we could almost touch them. They reveal their individuality and their personality. To see people from a distance is to see them in the way we would normally only see strangers, people whose lives do touch on ours. We see them in outline, impersonally, as types rather than as individuals. This does not mean of course that the people we see represented in close-up are actually close to us, or vice versa. It means they are represented as though they belong or should belong to "our group," and that the viewer is thereby addressed as a certain kind of person. (146) 
Distance or proximity, in other words, projects the possible relationship between the represented in the image and the viewer. Borrowing from electronic media's terminology, Jewitt and Oyama tell us:

[a] close-up (head and shoulders or less) suggests an intimate/personal relationship; a medium shot (cutting off the human figure somewhere between the waist and the knees) suggests a social relationship [...]; and a "long shot" (showing the full figure, whether just fitting in the frame or even more distant) suggests an impersonal relationship. (146)

\section{Why AcaiBurn?}

\section{Feel healthy and vibrant \\ Lose unwanted weight \\ Hollywood's hottest diet \\ Boosts energy levels \\ Your friends will be so jealous \\ Good bye one-piece...Hello Bikini \\ Clinically proven ingredients}
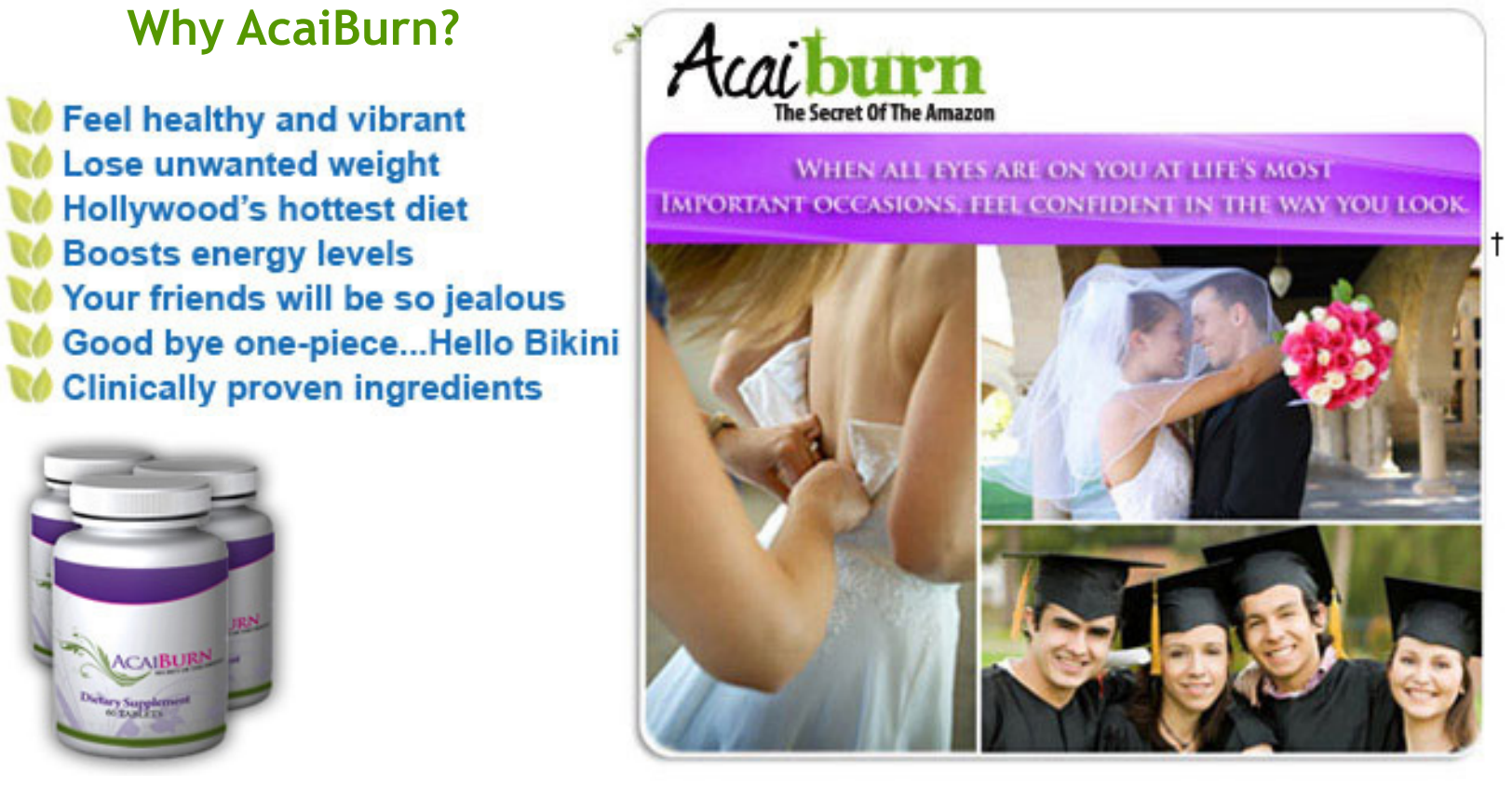

Fig. 3. All eyes are on you, Acaiburnmax.com, n.d. Web, 27 August 2009.

Figure 3 shows two sets of images. On the left, is the bulleted list for answering the question "Why AcaiBurn?"7 On the right, a composite of three snapshots depicts intermediate degrees between close-up (graduation) and medium distance photographs (wedding). The close-up graduation photograph shrinks the gap between those in the photo and those viewing it and enacts the possible personal relationship between the beaming graduates and the viewers. The personal distance projects that the represented is a group of four people who have successfully completed a degree. These graduates brim with a sense of accomplishment. The wedding photographs endorse the social norm of a heterosexual wedding representing a significant phase of human life. The viewers are reminded via the text on the top of the images that "when all eyes are on you at life's most important occasions, feel confident in the way you look." In these particular images, seemingly unrelated milestones of life and physical appearance are correlated. The (not so) 
subtle message is the ideological construct that a shapely body attains good graces from others when you experience "life's most important occasions" and that with a shapely body comes the "confidence" necessary for such occasions. The meaning potentials of visual and verbal messages are carefully drawn to engage the viewer's attention by means of the social distance.

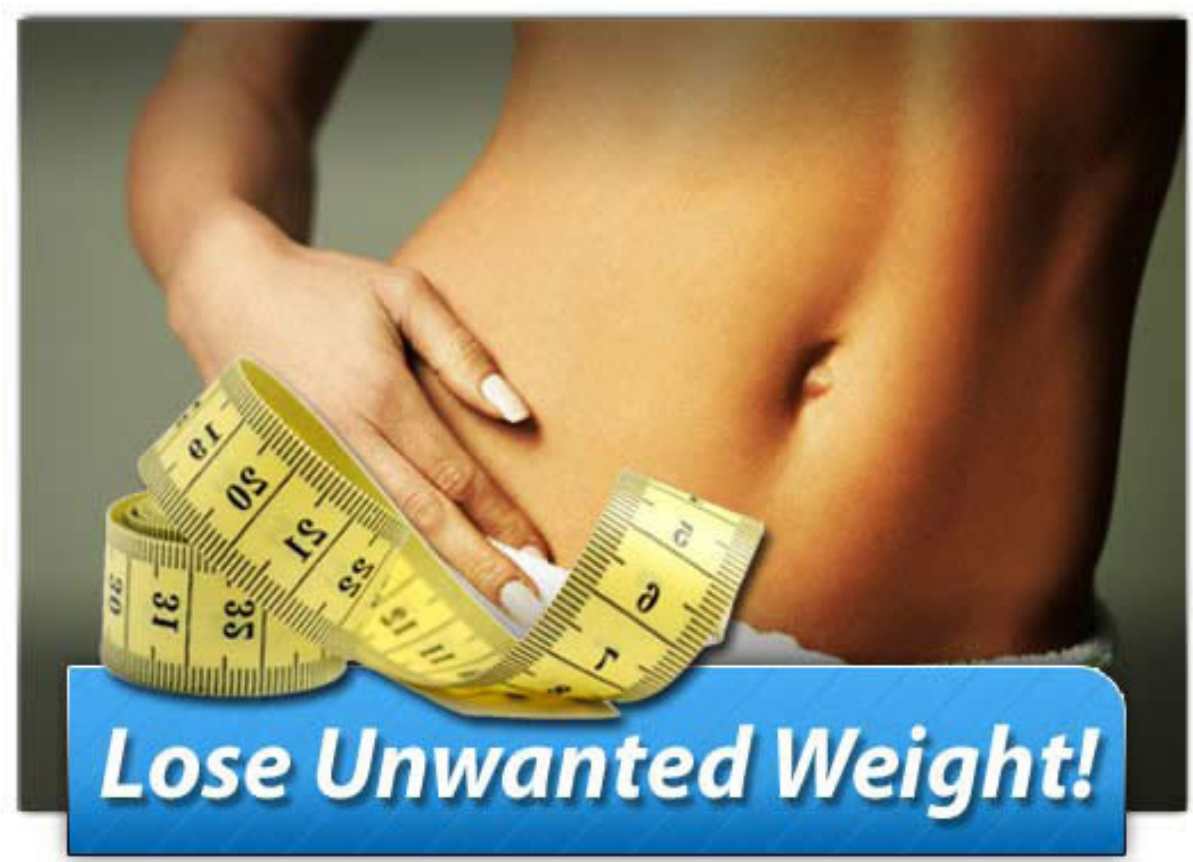

Fig. 4. Lose Unwanted Weight! Acaiburnmax.com, n.d. Web, 27 August 2009.

Figure 4 is a close-up photograph of the fully exposed mid-section of a female body. The distance between the represented and the viewer has shrunk. The right hand that gently touches the belly acts as a vector: "an oblique line, a quite strong, diagonal line [...] formed by bodies or limbs or tools 'in action', ... with explicit indicator of directionality, usually an arrowhead" (Kress and van Leeuwen 57). Based on Kress and van Leeuwen's notion of vectorial force, the hand directs the viewers to the important part of the photo: the abdomen, which leads the viewers' to desire for what is presented: a flat, slim, and shapely waistline. This kind of meaning potential does not even require a full length figure or facial identification. It plays on the semiotic strategy that considers a part or parts standing for the whole. Although the image seen here is merely a part standing for the whole female body, it is a very salient portrayal that grips one's attention. It endorses the slim and flat abdomen as attractive, desirable and perfect. With the written command of "Lose Unwanted Weight," the viewers are reminded that the slim and flat waistline is the only type that is acceptable and that a shapely body is possible through 
AcaiBurn products is reiterated. ${ }^{8}$ This close-up shot of a slim and flat waistline is effective in hooking viewers' attention; hence, the message of the desirability of a slim waistline is conveyed with no mention of the health advantages of weight loss. This is a partial message as the promotion of weight loss efforts are clinically endorsed for better health and not just for the aesthetic reasons. This, with other body management practices like dieting, exercising and cosmetic surgery, points to a culture which places an inordinate value on physical appearance as a measure of internal worth.

\section{Point of View}

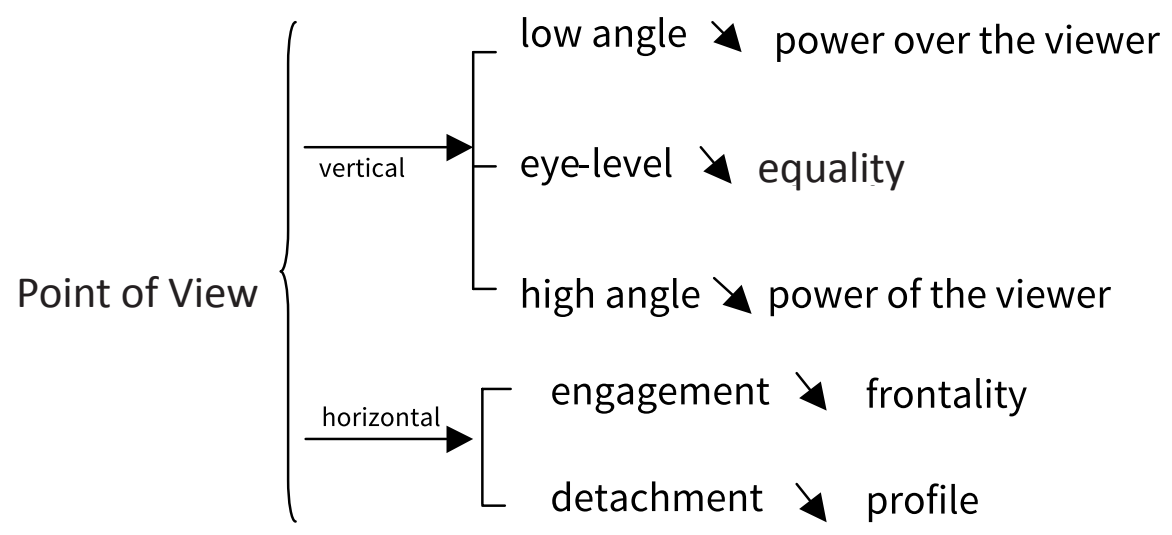

Fig. 5. "Point of View". Chart. Visual Meaning: A Social Semiotic Approach. Jewitt and Oyama. London: Sage Publications. 2001. 134-156. Print.

Another means of drawing out interactive meaning potentials is "point of view" (Kress and van Leeuwen 135-53). This can be drawn from horizontal or vertical dimensions. ${ }^{9}$ In Jewitt's study exploring the visual representation of male heterosexuality in British sexual health materials aimed at people aged 13 to 19 years old, she describes how ads of the horizontal dimension utilize frontal angles to increase audience identification and involvement with represented participants, and vertical angles to represent men as powerful in particular roles. Jewitt and Oyama clarify:

"power," "detachment," "involvement," and so on, are not "the" meanings of these angles. They are an attempt to describe a meaning potential, a field of possible meanings, which need to be activated by the producers and viewers of images. But this field of possible meanings is not unlimited. If you want to express that something or someone is impressive and powerful, you are unlikely to choose a high angle, and if you see someone depicted from a high angle, you are unlikely to conclude that he or she is represented as an impressive and powerful person. (135) 
The relationship between image viewers and the people, place or things represented in images can be dictated by the placement of objects in a picture. For instance, if a person or an object is placed on equal footing, it can symbolically make us relate as either an equal or in a detached manner. Nevertheless, it is important to remember that what appears in an image may not be entirely true, as Jewitt and Oyama remind us: "it [an image] can 'lie"; An image/photograph/picture is only a representation and functions at a symbolic level (135). Yet, even in this symbolic projection, the picture becomes the very ground where the viewers are taken in to believe the possibilities, ideals or parallels between what is represented. They further explain:

In the case of the vertical angle this relation will be one of symbolic power. If you look down on something, you look at it from a position of symbolic power. If you look up at something, that something has some kind of symbolic power over you. At eye-level there is a relation of symbolic equality. In the case of the horizontal angle, the relation will be one of involvement with, or detachment from, what is represented. Frontality allows the creation of maximum involvement. The viewer is directly confronted with what is in the picture. If something is depicted from the side, the viewer literally and figuratively remains on the sidelines. (135)

Let's find out from the following Figure 6 on how this works. On the right of Figure 6, we see a slim lady, in athletic attire and running on a meadow. On the left is a write-up on what to anticipate in taking a dose of Acaiburn from Day 1 right up to Week 4 and Beyond. Although the image on the right gives the impression that a good and ideal body figure is attained through exercising, the text on the left focuses more on the effectiveness of AcaiBurn in assisting successful weight loss.

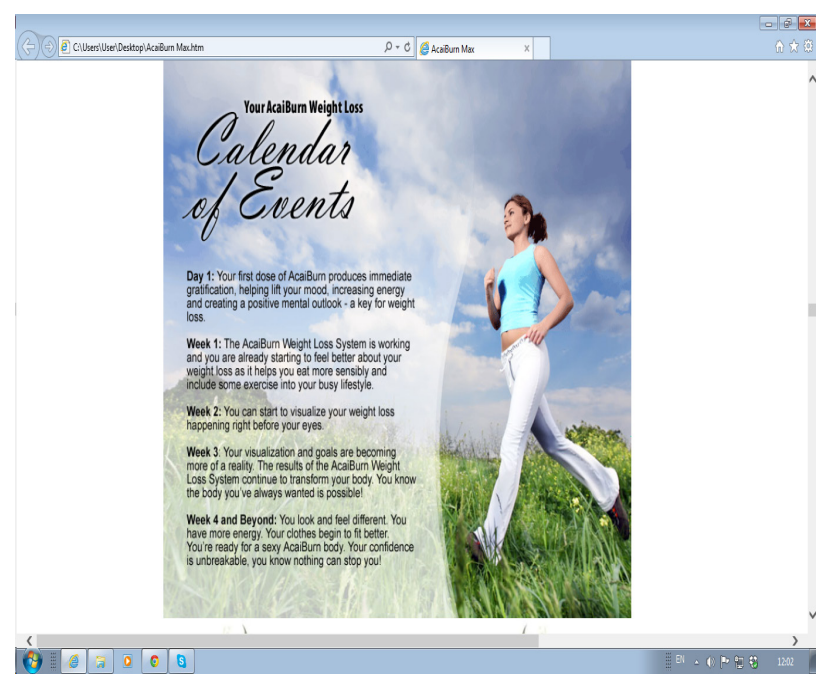

Fig. 6. Calendar of Events. Acaiburnmax.com, n.d. Web, 27 August 2009. 
Different points of view grant different meaning potentials. In Figure 6, the image of this lady is captured from the camera lens that is placed at the bottom. This creates a lower vertical angle that seems to highlight the long and slender legs of this lady jogger.

This low angle point of view creates a powerful image of a desirable female body silhouette - one that focuses her slim and lean limbs. When viewers look at this image, the angle of the image makes the viewer seems to look up at it. This image of this lady jogger has some kind of symbolic power over the viewers (Jewitt and Oyama 135). In this case, the lady jogger is a consumer of AcaiBurn that "lift[s] [her] mood", "[increases] energy" and "[creates] a positive mental outlook." As there is no eye-contact with the lady jogger, the viewers observe the image in a detached manner. Nevertheless, contact or relations are established through the verbal text. The written text works hand-in-glove with the image to entice the attention and imaginations of the viewers. Viewers are led to make the connection that when one consumes AcaiBurn products, she can "feel better," "eat more sensibly" (Week 1), "visualize [her] weight loss" (Week 2), "transform [her] body" (Week 3), and "look and feel different" (Week 4). What the image does is to concretize and support the text's claims.

\section{CONCLUSIONS}

This paper, therefore, is timely and significant as it uses a schema that is able to reveal the discourses of images. It also addresses the gaps in the existing literature on gender and visual culture research. By examining the portrayal of the female body through the lens of visual, social semiotics, it is a clarion call to how the female body is in crisis with the centrality of visual culture in our contemporary society.

Jewitt and Oyama's VSS method of analysis provides a descriptive framework for analysis of advertising images. But VSS by itself is not entirely sufficient. It does not, on its own, offer all that is needed for the sociological interpretation of images. To explain the results of the analysis, this study had to tap other sources, on social theories of gender and femininities (Wood; Wolf); on earlier studies of gender construction in images (Goffman; Barthel; Williamson) and of course, earlier studies of advertisement and female images (Grogan; Dyer). These sociological interpretations of images support the findings from the VSS analysis of advertising images. To begin with, throughout history, some women conformed to what was considered desirable body sizes: from rotund to emaciated (Albani; Ng; Moodyhall; Goodman; Seid). To be thin-waisted, women underwent torturous measures - whalebone corsets and even the surgical removal of the lower ribs - all in the name of fitting in with the social ideal (Hymowitz and Weisman). Today, instead 
of ribs, women resort to extreme methods to remove fat, including strenuous exercising regimes, anorexic and bulimic practices, and even body modification through cosmetic surgery. Fat removal is done in the name of attaining the ideal female body shape and size because women feel ill at ease with their bodies, and are in a constant state of dissatisfaction (Orbach). According to Wykes and Gunter, this dissatisfaction with the body image resides "within a discrepancy between the perceived self and ideal self" (4). The ideal self-image may be considered as either an "internal ideal" or a "societal ideal" resulting from the dictates of the surrounding cultural and societal environment as to what constitutes the perfect body. Perceived-ideal discrepancies that cause dissatisfaction in relation to aspects of the body that are regarded as malleable, such as weight and the distribution of fat, are believed often to provoke attempts to narrow this discrepancy through body management practices such as dieting, exercising and even body modification. Images do reinforce stereotyped forms of femininity by which women are persuaded and subjected to conform to cultural standards of beauty. The dominant representation of an ideal female body in the samples conveyed conventional hegemonic norms: physical attractiveness is everything; to be physically attractive equals high desirability, and physical attractiveness is what it takes to attain and hold onto relationships with friends, peers, and spouses. The female is expected to be slim in order to be attractive to men. She is the object of the male gaze when she has a slim waistline, and a happy life is hers only if she is slim. It is not surprising that women are perpetually preoccupied with their physical appearance. From the gender lens, this is but one of the innumerable harmful myths on the concept of "feminine beauty." Naomi Wolf, in her book, The Beauty Myth examines the ideas of beauty as propagated by the media at large, which in time, have been perpetuated as "manuals" to be adhered to (19). They function as a yardstick and demand that women to live up to their notions of beauty. Wolf informs that women across all ages in the West are deeply affected to conform to an idealized concept of female beauty. She further contends that the beauty myth is political: a means of maintaining the longstanding patriarchal system. In Wolf's words, these "images of female beauty [is as good] as a political weapon against women's advancement." (10). Post-war women have been liberated into the workforce yet continue to endure gender discrimination in society. Such a controlled system functions to keep womenfolk in their place, inferior and secondary to men, and discriminated against in terms of jobs, income and promotion. Wolf claims that this is done by keeping women under the weight of their own insecurities, particularly their physical appearance. Wolf brings to light that women suffer from paralyzing doubts about themselves that negatively affect their own self-esteem and self-worth. What we see in the $21^{\text {st }}$ century web-advertising is no different. Our culture and society's imposition on images of beauty, as found in various media, are detrimental to women, as well as men's view of women. Culture that implies that women are better off being dead than ugly-looking, old, or fat is grossly unjustified and reductive (Lau and Zuraidah). 
The VSS, as a descriptive framework for analysis of advertising images, is effective in bringing out hidden meanings. In the study of the AcaiBurn weightloss web-advertising, the method revealed gender representations which were not apparent in the written text, such as over-simplifications of feminine beauty. In the case of the three images above (Figures 2, 4, and 6), the advertiser's choices and strategies revealed gender representations which were not apparent in the verbal text, such as the idea of being overweight as a predominantly female problem (none of the images addresses male weight problems). Implicit in these images is the message that an overweight female will not gain male admiration, nor will she be confident at important occasions, nor will she get a chance to change her lifestyle. This clearly reinforces society's message that women, not men, must attain certain stereotypical beauty ideals in order to be feel beautiful, desirable and confident. With the over-simplification of such messages, the predominant ideological constructs of feminine beauty are maintained, perpetuated and legitimized.

As we can see, VSS can play an important role in the examination of images in advertisements. This descriptive framework helps to illuminate how the structures of images contribute to the representation of concepts of female beauty. Images, in any form (print or multimedia), can create complex and subtle relations between the represented and the viewers as seen through the three key interactive dimensions: distance, contact, and point of view. Echoing Jewitt and Oyama, that which is represented in the images can "interact with viewers and suggest the attitude viewers should take towards what is being represented" (145). As viewers, we are not passive. We interact with the images presented right before us and see how the female body is inevitably in crisis: women are drawn to the images of the slim and trim ideal; if they fail to meet these expectations as conveyed in the advertising messages, they are likely to think less of themselves.

The discussion above offers a case in point that the advertiser stresses the visual oversimplification of feminine beauty, the visual polarization of men's and women's roles, and the visual legitimating of a narrow definition of male and female sexuality. We are living in an imaged-based culture that not only celebrates youthfulness and thinness, but also defines the identity of people as individuals in terms of what they possess, buy, or look like. Representations of idealized bodies in weight-loss advertising construct a visual reality to convince women that what they see is real and achievable. By providing insights on how the visuals in advertisement construct the notions of what it means to be a beautiful and attractive woman, it is hoped that such portrayal will be understood as socially constructed and supported by the dominant visual and written discourses in the weight-loss advertisement. In 
that way, women will learn to accept their bodies as nature intended it and to be empowered to resist the ideology of the slim ideal, the tyranny of the thin appeal and be less critical and more sympathetic towards those who look different from idealized women in web-advertisements.

\section{NOTES}

1. This website is no longer accessible. However, the data captured for this paper is with the author. Should there be any inquiry regarding the information from this obsolete website, kindly contact the author.

2. This critical visual analysis to discover meaning potentials follows the work of Kress and van Leeuwen in using "system networks," a style of diagramming that derives from the work of M.A.K Halliday, whose linguistic theories have been a decisive influence on this kind of visual analysis. Kress and van Leeuwen have "extended this idea to images, using a slightly different terminology: 'representational' instead of 'ideational;' 'interactive' instead of 'interpersonal;' and 'compositional' instead of 'textual." For further details, see Kress and van Leeuwen.

3. There are three principal dimensions of visual semiosis in relation to the image: (1) representational, (2) interactional, and (3) compositional. The representational and compositional dimensions also contribute to meaning potentials. Each dimension highlights the same issue from a different angle. As Nalon reminds us, "the multimedia dimension of a text and specifically of ads, does not consist of a random combination of various modes: each semiotic mode conveys meanings that are specific to itself and those meanings somehow blend into the construction of the overall message (9-10)." With that in mind, it is useful to note that each dimension contributes to the overall meaning. In fact, for a comprehensive analysis, it is best when all three are employed together. However, the scope of this paper focuses specifically on the interactive meaning potentials in web-advertising in order to illustrate how the present-day female body is in crisis.

4. The viewer here refers to person/people who viewed the image. Kress and van Leeuwen see "interactive meanings are visually encoded in ways that rest on competences shared by producers and viewers (120-121)." It also goes to mean that the values and beliefs of the producer or image-maker are encoded in the structures of the images (Jewitt 273). Hence, the viewer is accorded with the agency to contest or embrace the values and beliefs of the image-maker.

5. Laura Mulvey's seminal paper discloses how the cinematic world creates a number of pleasures. One of which is scopophilia. Mulvey describes two sides of scopophilia, "circumstances in which looking itself is a source of pleasure" and "pleasure in being looked at." These two sides have been polarized into the male or active viewer and the female or passive image. Here, the idea of "male gaze" begins to take shape (4). Mulvey postulates that cinematic images encode 
female erotic and sensual appeal as a function of a woman's "to-be-looked-atness" (4). In short, to be feminine is to be looked at, with sexual desire, by a man. And what constitutes "to-be-looked-at-ness" by the advertising world is the perfect body and flawless youthful look, an oversimplified idea that reduces women's entire being to mere physical attractiveness.

6. Although AcaiBurn is not seen in Figure 2 itself, it appears on top of it (see below, Figure 7). There are two images: on the left, AcaiBurn products are seen with the question, "Why AcaiBurn?" and seven reasons are provided; on the right, there is a picture of a family having fun at a beach setting. In a way, the image on the left with the seven reasons (i.e.: effectiveness of AcaiBurn products) serve to reinforce the message by the woman in white (Figure 2).
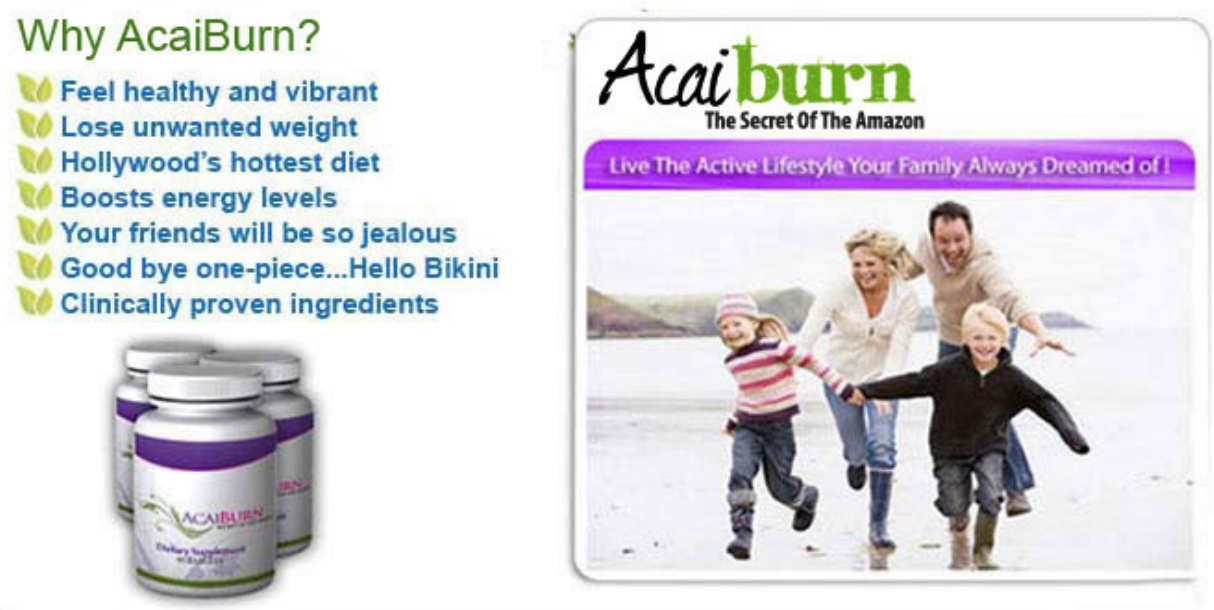

Fig. 7. Live the active lifestyle your family always dreamed of! Acaiburnmax.com, n. d. Web, 27 August 2009.

7. This image is not considered for analysis as it does not have any portrayal of the female body.

8. Again, we do not see the AcaiBurn products in Figure 4 itself. However, Figure 8 appears before this image (see below). It is interesting to note that the verbiage on the left says that, "Everyone will notice (but no one will know)." And then, the AcaiBurn icon follows, "AcaiBurn: The Secret of the Amazon." The bottom band shows the six icons of search engines or news channels where information on AcaiBurn products can be found. This works to lend credibility and legitimacy to the AcaiBurn products. On the right of Figure 8, it is a close shot of an anonymous woman with huge hat and sunglasses. She appears to signal a silence sign to the viewers by placing her index finger on her lips, it further reinforces how only she and the viewers exclusively share this "secret" of weight-loss by using AcaiBurn products. 


\section{Everyone Will Notice \\ (but no one will know)}

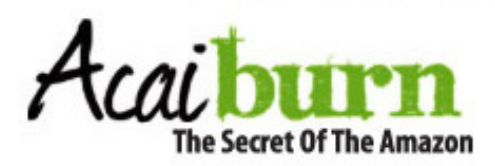

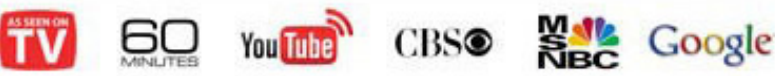

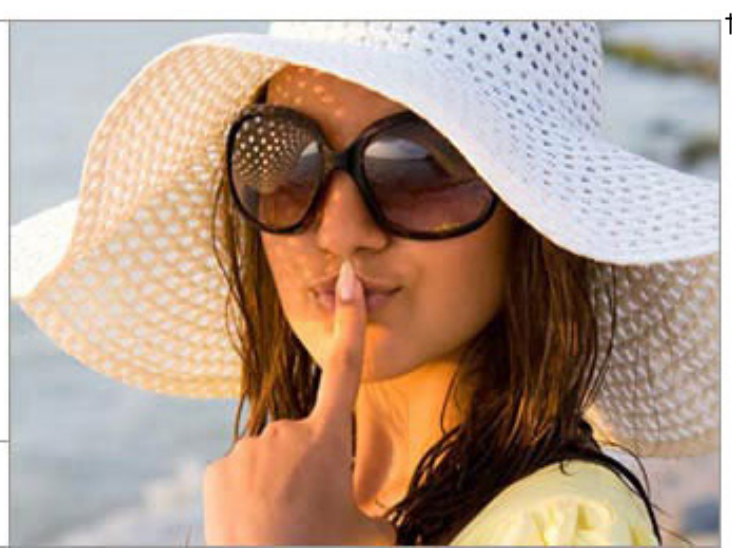

Fig. 8. Everyone will notice. Acaiburnmax.com, n.d. Web, 27 August 2009.

9. Jewitt and Oyama further explain that: [t]his resource allows people, places and things to be depicted from above (or at eye-level), and from the front, the side or the back. Both these dimensions, the vertical and the horizontal, are graded, a matter of degree. There is, for instance, a range of vertical angles between the 'bird's eye' view and eye-level, and a range of horizontal angles between frontality and the profile (135). 


\section{WORKS CITED}

Acaiburn: The secret of the Amazon, n.p. n.d. Web. 27 August 2009.

Albani, Francesca. Thinness Matters: The Impact of Magazine Advertising on the Contemporary Beauty Ideal. M.A. Thesis. Ohio: Miami University, 2005. Print.

Barthel, Diane. Putting on Appearances: Gender and Advertising. Philadelphia: Temple UP, 1988. Print.

Bartky, Sandra. "Foucault, Femininity and the Modernization of Patriarchal Power." Feminist Social Thought: A Reader. Ed. Diana Tietjens Meyers. London: Routledge, 1997: 92-111. Print.

Bordo, Susan. Unbearable Weight: Feminism, Western Culture and the Body. Berkeley: U of California P, 2003. Print.

Bovee, Courtland and William Arens. Contemporary Advertising. Chicago: Irwin Inc., 1986. Print.

Budgeon, Shelley. "Fashion Magazine Advertising: Constructing Femininity in the

'Postfeminist' Era." Ed. Luigi Manca and Alessandra Manca. Gender and Utopia in Advertising: A Critical Reader. Lisle: Procopian Press, 1994: 55-70. Print.

Caqueo-Urízar, Alejandra, Marta Ferrer-García, José Toro, José Gutiérrez-Maldonado, Claudia Peñaloza, Yasna Cuadros-Sosa, and Ma José Gálvez-Madrida. "Associations between Sociocultural Pressures to be Thin, Body Distress and Eating Disorder Symptomatology among Chilean Adolescent Girls." Body Image 8 (2011): 78-81. Print.

Cohen, Barbara. "The Psychology of Ideal Body Image as an Oppressive Force in the lives of Women." Healingthehumanspirit.com. n.p., 2001. Web. 18 July 2010.

Duffy, Margaret. "Body of Evidence: Studying Women and Advertising." Ed. Luigi Manca and Alessandra Manca. Gender and Utopia in Advertising: A Critical Reader. Lisle: Procopian Press, 1994: 5-30. Print.

Dyer, Greg. Advertising as Communication. London: Metheun, 1982. Print.

Friedan, Betty. The Feminine Mystique. Harmondsworth: Penguin, 1965. Print.

Goodman, Robyn Potter. Mirroring Mediated Images of Women: How Media Images of Thin Women Influence Eating Disorder-related Behaviors and How Women Negotiate these Images. Ph.D Thesis. Austin: University of Texas, 20oo. Print.

Goffman, Erving. Gender Advertisements. London: Macmillan, 1979. Print.

Grogan, Susan. Body Image: Understanding Body Dissatisfaction in Men, Women and Children. New York: Routledge, 2007. Print.

Halliday, Michael. Language as Social Semiotic. London: Edward Arnold, 1978. Print. Hymowitz, Carol and Michaele Weissman. A History of Women in America. New York: Bantam Books, 1978. Print.

Jewitt, Carey. "A Social Semiotic Analysis of Male Heterosexuality in Sexual Health Resources: The Case of Images." International Journal of Social Research Methodology: Theory and Practice 1.4 (1999): 263-80. Print.

Jewitt, Carey and Rumiko Oyama. "Visual Meaning: A Social Semiotic Approach." Handbook of Visual Analysis. Ed. Theo van Leeuwen and Carey Jewitt. London: Sage Publications, 2001: 134-156. Print. 
Kress, Gunther and Theo van Leeuwen. Reading Images: The Grammar of Visual Design. London: Routledge, 1996. Print.

Lau, Emily Kui Ling. "The Construction of the Ideal Female Body: A Critical Discourse Analysis of Malaysian Slimming Advertisements." Ph.D Thesis. Kuala Lumpur: University of Malaya, 2013. Print.

Lau, Emily Kui Ling and Zuraidah Mohd. Don. "Fat Stigmatisation in Slimming Advertisements in Malaysia." SEARCH: The Journal of the South East Asia Research Centre for Communication and Humanities 5.3 (2013): 1-19. Print.

Leuvorasirikul, Kanokrat. Body Image and Weight Management: Young People, Internet Advertisements and Pharmacists. Ph.D. Thesis. England: University of Nottingham, 2007. Print.

Moody-Hall, Mia. Magazine Advertisements' Influence on Body-Image Satisfaction Based on Race, Gender and Socioeconomic Status. M.A. Thesis. Waco, Texas: Baylor University, 2001. Print.

Mulvey, Laura. "Visual Pleasure and Narrative Cinema." Screen 16.3 (1975): 6-18. Web. 21 Jan. 2010.

Myer, Philip and Frank Biocca. "The Elastic Body Image: The Effect of Television Advertising and Programming on Body Image Distortion in Young Women." Journal of Communication 42.3 (1992): 108-133. Print.

Ng, Bo-Sze. Slimming Culture in Hong Kong: A Sociological Study. M.A. Thesis. Hong Kong: University of Hong Kong, 2005. Print.

O'pry, Amy Suzanne. Relationship of Magazine Advertisements to Male Body Image and Body Shame. Ph.D Thesis. Pasadena, Texas: Texas A \& M University, 2003. Print.

Orbach, Susie. Fat is a Feminist Issue. London: Arrow Books, 2006. Print.

--.. Bodies: Big Ideas, Small Books. New York: Picador, 2009. Print.

Pienaar, Kiran. "A Critical Analysis of Oppositional Discourses of the Ideal Female Body in Women's Conversations." M.A. Thesis. Canada: Rhodes University, 2006. Print.

Seid, Roberta Pollack. Never Too Thin: Why Women are at War with their Bodies. New York: Prentice Hall Press, 1989. Print.

Stice, Eric and Heather Shaw. "Adverse Effects of the Media-portrayed Thin-ideal on Women and linkages to Bulimic Symptomatology." Journal of Social and Clinical Psychology 13 (1994): 288-308. Print.

Tan, Sabine. "Modelling Engagement in a Web-based Advertising Campaign." Visual Communication 9.1 (2010): 91-115. Print.

Tao, Mei, Xian-Sheng Hua, and Shipeng Li. "Contextual in-image advertising. "Proceedings of the 16th ACM International Conference on Multimedia (ACM MM), 26-31 Oct 2008. Vancouver: Canada, 2008. 439-448. Print.

van Leeuwen, Theo and Carey Jewitt. Eds. Handbook of Visual Analysis. London: Sage, 2001. Print.

Veale, David. "Advances in a Cognitive Behavioural Model of Body Dysmorphic Disorder". Body Image 1 (2004): 113-25. Print.

Williamson, Judith. Decoding Advertisements: Ideology and Meaning in Advertising. London: Marion Boyars, 1978. Print. 
Wolf, Naomi. The Beauty Myth: How Images of Beauty are used against Women. New York: HarperCollins Publishers, 2002. Print.

Wykes, Maggie and Gunter, B. The Media and Body Image: If Looks could Kill. London: Sage, 2005. Print. 